\title{
Heavy Robots for C-IED Operations
}

\author{
Marian Janusz LOPATKA
}

\author{
Military University of Technology, Institute of Mechanical Engineering, 2 gen. Witolda \\ Urbanowicza Street, 00-908, Poland \\ E-mail:marian.lopatka@wat.edu.pl
}

\begin{abstract}
This paper the contain description of possibility of future combat engineer task robotization. The analysis is focused on most dangerous task like engineer obstacle breaching including mine fields, fence and other barriers. In the paper are described proposals of new technics and tactics for using robots and demand for their new possibilities
\end{abstract}

KEY WORDS: military robots, unmanned ground vehicles, combat engineer tasks, improvised explosive device, C-IED operation

\section{Introduction}

In recent years, the rapid development of combat engineer UGV, also called EOD robots and the scope of their range of uses has been observed. Their widespread use in the army was initiated by the conflict in Iraq due to the massive use of IEDs (Improvised Explosive Device). They were mainly used to the confirming the presence of IEDs, their identification and neutralization. Because the scope of the tasks carried out was similar to those performed by police pyrotechnics initially the pyrotechnic robots available on market were used for it. It quickly became clear that their usefulness is limited because their basic task was quick verification of the occurrence of a threat - usually the suspicious object was at a distance of 100-200 meters. Unfortunately, a long time to prepare the robot for work (Removal of transportation safety rolling off of the transport) and low speed (usually 1-2 km / h) did not provide the necessary efficiency of use. They were also not designed for intensive work in field conditions. Hence, in relatively short time the significantly lighter robots were introduced (weight approx. 20-60 kg in relation to approx. $300 \mathrm{~kg}$ of pyrotechnic robots) and faster (driving speed increased to $8-10 \mathrm{~km} / \mathrm{h}$ ) better suited to moving in a terrain. Their main purpose is recognition and identification of threats. In favorable conditions, they may also attempt neutralization. However, their capabilities in this area are much smaller than pyrotechnic robots due to the simplified manipulators construction and small lifting capacity. As a result, in American EOD subunits (Explosive Ordnance Disposal) with the largest experience in using robots, three types of robots are widely used:

- MK-1 - Packbot 510 (Endeavor Robotics) with a weight depending on the version;20-25 kg;

- MK-2 - Talon IV (Foster-Miller) with a weight depending on the version;50-70 kg;

- MK-3 - Andros (Northrop Grumman Remotec) with a weight depending on the version;300-350 kg.

Light robots (MK - 1, MK 2) are usually used in maneuvering operations, e.g. as part of RCP (Route Clearance Patrol), while robots with extensive manipulation functions (MK-3) and lifting capacities up to $27 \mathrm{~kg}$ on the maximum range $(1,4 \mathrm{~m})$ are used for neutralization IEDS in urban area on firm grounds.

Operational possibilities of these robots are too small for effective taking and neutralization UXO (Unexploded Ordnance) - what is equally important task of the EOD subunits, because the weight of bombs and missiles can be $200-250 \mathrm{~kg}$, and even up to $500 \mathrm{~kg}$. Taking artillery shells and mortar grenades may also require large lifting forces at maximum range, when they are in a hard-to-reach place or driven into the ground. Additional difficulties may be caused by the necessity of digging them and removal in rough terrain. For these reasons, it is necessary to develop heavy EOD robots, with high lifting capacity and high terrain mobility - capable of long -term work in as rough terrain.

\section{Heavy Robots EOD}

Even a cursory analysis indicates that there are machines available on the market for working in difficult terrain and having the necessary accessories, tools and lifting capacity. These are tracked mini loaders and tracked mini excavators with its weight 2-5 t. The easiest and the cheapest way to obtain heavy EOD robots is their robotization (tab.1) - adaptation to remote control in teleoperation mode.

One of the first of such solutions was the ARTS (All-Purpose Remote Transport System) system using the Posi Track RT-50 loader with a weight of approx. $3000 \mathrm{~kg}$. Thanks to the standard quick-coupling it can use about 100 commercial tools available on the market and work with tools specially designed for engineering works. It is currently equipped with the US military forces. The advantage of compact track loaders is the standard quick-coupling, great pulling power, very high maneuverability (possibility of turning back in place) and relatively high speed. 


\begin{tabular}{|c|c|c|c|c|}
\hline ROBOT & $\begin{array}{l}\text { Spartacus - T110 } \\
\text { (Qinetiq/Bobcat) }\end{array}$ & $\begin{array}{l}\text { Scorpion } \\
\text { (Autonomous } \\
\text { Solution/Bobcat) }\end{array}$ & $\begin{array}{l}\text { Micro MineWolf } \\
\text { MW50 } \\
\text { (Pearson Enginering) }\end{array}$ & $\begin{array}{l}\text { Rhino } \\
\text { (MUT/WB Electronic) }\end{array}$ \\
\hline mss & ok. $2400 \mathrm{~kg}$ & $3300 \mathrm{~kg}$ & ok. $2000 \mathrm{~kg}$ & $3000 \mathrm{~kg}$ \\
\hline power & $29 \mathrm{~kW}$ & $24 \mathrm{~kW}$ & $36 \mathrm{~kW}$ & $46 \mathrm{~kW}$ \\
\hline width & $120 \mathrm{~cm}$ & $152 \mathrm{~cm}$ & $100 \mathrm{~cm}$ & $200 \mathrm{~cm}$ \\
\hline $\begin{array}{l}\text { lenght (without } \\
\text { equipment) }\end{array}$ & $226 \mathrm{~cm}$ & $198 \mathrm{~cm}$ & $230 \mathrm{~cm}$ & $280 \mathrm{~cm}$ \\
\hline $\begin{array}{l}\text { hight (without } \\
\text { manipulators) }\end{array}$ & $188 \mathrm{~cm}$ & $243 \mathrm{~cm}$ & $140 \mathrm{~cm}$ & $130 \mathrm{~cm}$ \\
\hline $\begin{array}{l}\text { range of teleoperation } \\
\text { LOS }\end{array}$ & $1000 \mathrm{~m}$ & $1000 \mathrm{~m}$ & $1000 \mathrm{~m}$ & $1300 \mathrm{~m}$ \\
\hline speed & $8,4 \mathrm{~km} / \mathrm{h}$ & $4,7 \mathrm{~km} / \mathrm{h}$ & $6 \mathrm{~km} / \mathrm{h}$ & $30 \mathrm{~km} / \mathrm{h}$ \\
\hline work time & $10 \mathrm{~h}$ & $10 \mathrm{~h}$ & $10 \mathrm{~h}$ & $10 \mathrm{~h}$ \\
\hline $\begin{array}{l}\text { load capacity } \\
\text { ( without } \\
\text { manipulators) }\end{array}$ & - & - & $400 \mathrm{~kg}$ & $1000 \mathrm{~kg}$ \\
\hline $\begin{array}{l}\text { Replacement of } \\
\text { working equipment }\end{array}$ & $\begin{array}{l}\text { loader equipment } \\
\text { with quick- coupling }\end{array}$ & $\begin{array}{l}\text { excavation equipment } \\
\text { with quick- coupling }\end{array}$ & tractor connector & $\begin{array}{l}\text { loader equipment with } \\
\text { quick- coupling } \\
\text { manipulator with } \\
\text { gripper }\end{array}$ \\
\hline tools & $\begin{array}{l}\text { grapple bucket } \\
\text { multifunctional } \\
\text { bucket } \\
\text { forklift } \\
\text { plough }\end{array}$ & $\begin{array}{l}\text { bucket, gripper, } \\
\text { hammer, drill, } \\
\text { desruptor }\end{array}$ & $\begin{array}{l}\text { excavation equipment / } \\
\text { manipulator } \\
\text {-bucket, gripper, } \\
\text { desruptor } \\
\text { flail - width } 1.2 \mathrm{~m}\end{array}$ & $\begin{array}{l}\text { grapple bucket } \\
\text { multifunctional bucket } \\
\text { forklift } \\
\text { plough }\end{array}$ \\
\hline $\begin{array}{l}\text { MANIPULATOR } \\
\text { degrees of freedom } \\
\text { (DOF) }\end{array}$ & $\begin{array}{l}\text { lifting the boom } \\
\text { closing the bucket } \\
\text { tool drive }\end{array}$ & $\begin{array}{l}\text { rotation of the boom } \\
\text { lifting the boom } \\
\text { raising the arm } \\
\text { lifting the gripper } \\
\text { rotation of the gripper } \\
\text { closing the gripper }\end{array}$ & $\begin{array}{l}\text { rotation of the boom } \\
\text { lifting the boom } \\
\text { raising the arm } \\
\text { arm telescope } \\
\text { lifting the gripper } \\
\text { rotation of the gripper } \\
\text { closing the gripper }\end{array}$ & $\begin{array}{l}\text { rotation of the boom } \\
\text { lifting the boom } \\
\text { raising the arm } \\
\text { lifting the gripper } \\
\text { rotation of the gripper } \\
\text { closing the gripper }\end{array}$ \\
\hline $\begin{array}{l}\text { range of the } \\
\text { manipulator }\end{array}$ & $0,7 \mathrm{~m}$ & $4,85 \mathrm{~m}$ & $\begin{array}{l}3,0 \mathrm{~m}+0,7 \mathrm{~m} \\
\text { teleskoping }\end{array}$ & $4 \mathrm{~m}$ \\
\hline $\begin{array}{l}\text { load capacity for max. } \\
\text { reach }\end{array}$ & $\begin{array}{l}\text { boucket }-500 \mathrm{~kg} \\
\text { fork- } 500 \mathrm{~kg}\end{array}$ & $200 \mathrm{~kg}$ & $400 \mathrm{~kg}$ & $\begin{array}{l}\text { manipulator - } 200 \mathrm{~kg} \\
\text { fork }-1000 \mathrm{~kg}\end{array}$ \\
\hline
\end{tabular}

On smooth surfaces they can reach speeds of approx. $10 \mathrm{~km} / \mathrm{h}$. In rough terrain due to the low longitudinal stability it drops to $3-5 \mathrm{~km} / \mathrm{h}$. However, the driving speed of a mini excavator in favorable conditions does not usually exceed 2-3 km / h. Their ability to overcome obstacles is also much smaller. The main advantage of mini excavators is greater manipulator work and greater lifting capacity due to the use of stabilizers supports. Therefore, they are used for tasks where a large range is necessary, and the work is of a stationary nature (low share of journeys in the implementation of the task).

Initially, the main problem of robotization was the combination of electronic remote-control systems with hydraulic drives. However, after the popularization of the Load-Sensing hydraulic drive controlled in the CAN bus system, this is not a problem. For example, all Bobcat mini-machines equipped with Selectable Joystick Controls (SJC) are currently adapted for remote control. It is only necessary to develop an appropriate system of teleoperation (table 1).

Such solutions are relatively cheap and reliable, but poorly adapted to specific engineering tasks. Hence, a number of attempts have been made to develop engineering robots that are better suited to anticipated tasks. An example is the tracked robot ACER (Armored Combat Engineer Robot) from Mesa Robotic with its weight $2040 \mathrm{~kg}$, lifting arm capacity of $454 \mathrm{~kg}(1,000 \mathrm{lbs}$.) and payload capacity of $1139 \mathrm{~kg}(2,500 \mathrm{lbs}$.), driven by $62 \mathrm{hp}$ turbocharged diesel engine. It can develop $10 \mathrm{~km} / \mathrm{h}$ and is characterized by very good longitudinal and transverse stability. Thanks to a special quickcoupling, it can work with various tools such as paving passes in engineering constructed obstacles.

A similar purpose - making the passes in the engineering dams has the Israeli robot "Avantguard". It was designed 
and made by G-NIUS. It is a platform with 8-wheel drive system, on which four mounted tracks are mounted. The torsion steering system ensures excellent maneuverability in difficult terrain conditions. The robot develops maximum velocities of $20 \mathrm{~km} / \mathrm{h}$, and it can autonomously detect and avoid obstacles. Cameras placed on a special rotary head allow observation of the terrain in the range of $3600^{\circ}$. A platform with a weight of over $1700 \mathrm{~kg}$ has the option of mounting on its chassis such sensors as a ground penetrating radar (GPR), interference devices and thermal and infra-red imaging systems or neutralization systems with a total weight of $1000 \mathrm{~kg}$.

A slightly different scope of tasks is carried out by the Israeli platform "Gardium". It allows to conduct a patrol along a road or fence in the autonomous mode (detecting intruders, navigating without access to GPS, avoiding obstacles on the road, etc.) at a speed of $7-8 \mathrm{~km} / \mathrm{h}$. It can be equipped with daylight and infrared cameras, radar, CBRN sensors, tracking detectors, road detectors and remote-controlled equipment. At a weight of 1,400 kg (length 2,95 m, width 1,8 m, height $2,2 \mathrm{~m}$ ) can develop a maximum speed of $50 \mathrm{~km} / \mathrm{h}$ (in the mode of teleoperation). It is built on the basis of a UTV off-road vehicle with a $4 \times 4$ wheeled driving system and a drive system with a CVT transmission. Its task is to detect changes in the environment indicating the activity of the opponent.

Characteristics of selected EOD robots weighing $600-800 \mathrm{~kg}$

Table 2

\begin{tabular}{|c|c|c|c|c|}
\hline ROBOT & $\begin{array}{l}\text { Protector } \\
(\text { HDT })\end{array}$ & $\begin{array}{l}\text { RS1-G2 } \\
\text { (Howe and Howe) }\end{array}$ & BPL - intervention 1$)$ & $\mathrm{BPL}$ - patrol ${ }^{1)}$ \\
\hline mass & ok. $800 \mathrm{~kg}$ & ok. $800 \mathrm{~kg}$ & $800 \mathrm{~kg}$ & $800 \mathrm{~kg}$ \\
\hline power & $24 \mathrm{~kW}$ & - & $20 \mathrm{~kW}$ & $20 \mathrm{~kW}$ \\
\hline width & $8 \mathrm{~km} / \mathrm{h}$ & $8 \mathrm{~km} / \mathrm{h}$ & $15 \mathrm{~km} / \mathrm{h}$ & $15 \mathrm{~km} / \mathrm{h}$ \\
\hline $\begin{array}{l}\text { length (without } \\
\text { equipment) }\end{array}$ & $90 \mathrm{~cm}$ & $107 \mathrm{~cm}$ & $200 \mathrm{~cm}$ & $125 \mathrm{~cm}$ \\
\hline $\begin{array}{l}\text { Hight (without } \\
\text { manipulators) }\end{array}$ & $193 \mathrm{~cm}$ & $186 \mathrm{~cm}$ & $280 \mathrm{~cm}$ & $380 \mathrm{~cm}$ \\
\hline $\begin{array}{l}\text { range of teleoperation } \\
\text { LOS }\end{array}$ & $107 \mathrm{~cm}$ & $102 \mathrm{~cm}$ & $180 \mathrm{~cm}$ & $180 \mathrm{~cm}$ \\
\hline speed & - & - & $800 \mathrm{~m}$ & $800 \mathrm{~m}$ \\
\hline work time & $10 \mathrm{~h}$ & $10 \mathrm{~h}$ & $10 \mathrm{~h}$ & $10 \mathrm{~h}$ \\
\hline $\begin{array}{l}\text { load capacity (without } \\
\text { manipulators) }\end{array}$ & $227 \mathrm{~kg}$ & ok. $400 \mathrm{~kg}$ & $450 \mathrm{~kg}$ & $450 \mathrm{~kg}$ \\
\hline $\begin{array}{l}\text { Replacement of } \\
\text { working equipment }\end{array}$ & $\begin{array}{l}\text { excavation equipment } \\
\text { with quick- coupling }\end{array}$ & $\begin{array}{l}\text { tractor connector } \\
\text { connection plate }\end{array}$ & $\begin{array}{l}2 \text { quick- coupling } \\
\text { - from two sides of } \\
\text { the carrier }\end{array}$ & $\begin{array}{l}2 \text { quick- coupling } \\
\text { - from two sides of the } \\
\text { carrier }\end{array}$ \\
\hline tools & $\begin{array}{l}\text { excavator bucket } \\
\text { (about } 15 \mathrm{dm} 3 \text { ) } \\
\text { loader bucket (56 } \\
\text { dm3) } \\
\text { flail (width } 0,6 \mathrm{~m} \text { ) }\end{array}$ & $\begin{array}{l}\text { manipulator - gripper, } \\
\text { desruptor } \\
\text { quick-coupling -fork } \\
\text { equipment (capacity } \\
227 \mathrm{~kg} \text { ) blade (width } \\
1,2 \mathrm{~m} \text { ) }\end{array}$ & $\begin{array}{l}\text { intervention } \\
\text { manipulator } \\
\text { - gripper } \\
\text { - multifunctional } \\
\text { bucket } \\
\text { - ripper tooth } \\
\text { - desruptor } \\
\end{array}$ & $\begin{array}{l}\text { inspection manipulator } \\
\text { detection system with } \\
\text { GPR }\end{array}$ \\
\hline $\begin{array}{l}\text { MANIPULATOR } \\
\text { degrees of freedom } \\
\text { (DOF) }\end{array}$ & $\begin{array}{l}\text { rotation of the boom } \\
\text { lifting the boom } \\
\text { raising the arm } \\
\text { lifting the gripper } \\
\text { closing the gripper }\end{array}$ & $\begin{array}{l}\text { rotation of the boom } \\
\text { lifting the boom } \\
\text { raising the arm } \\
\text { lifting the gripper } \\
\text { rotation of the gripper } \\
\text { closing the gripper }\end{array}$ & $\begin{array}{l}\text { rotation of the boom } \\
\text { lifting the boom } \\
\text { lifting arm } 1 \text { and } 2 \\
\text { lifting the gripper } 1 \\
\text { and } 2 \\
\text { rotation of gripper } 1 \\
\text { and } 2 \\
\text { closing the gripper } 1 \\
\text { and } 2\end{array}$ & $\begin{array}{l}\text { rotation of the boom } \\
\text { lifting the boom } \\
\text { raising the arm } \\
\text { closing the gripper lifting } \\
\text { the mast of the camera }\end{array}$ \\
\hline $\begin{array}{l}\text { range of the } \\
\text { manipulator }\end{array}$ & ok. $2,3 \mathrm{~m}$ & ok. $1,5 \mathrm{~m}$ & $3 \mathrm{~m}$ & $4.2 \mathrm{~m}$ \\
\hline $\begin{array}{l}\text { load capacity for max. } \\
\text { reach }\end{array}$ & $90 \mathrm{~kg}$ & ok. $100 \mathrm{~kg}$ & $80 \mathrm{~kg}$ or $240 \mathrm{~kg}$ & $10 \mathrm{~kg}$ \\
\hline
\end{tabular}

1) - under development 
The Micro MineWolf robot (table 1) has a completely different destiny. It is a miniaturized version of the 9-meter MineWolf machine, mainly used for humanitarian de-mining. Its task is to intervene in the event of an IED type threat. Thanks to the quick-coupling, it can have two engineering equipment - flail and a digging manipulator, gripping and neutralization with disrupter. Despite its armor, its mass with equipment does not exceed $2500 \mathrm{~kg}$. Due to its low weight and small dimensions, it ensures high transportability and can be used by RCP. Supports provide him with a large lifting capacity. However, the speed of travel and the ability to overcome obstacles are limited due to the rigid running gear.

A similar range of applications has been developed by WB-Electronic in cooperation with the Military University of Technology (MUT) robot "Rochatyniec" (Rhino) - tab.1. It is intended for interventions by means of a manipulator with a grapple or loader equipment. Thanks to the standard quick-coupling it is possible to use commercial tools for compact track loaders. The innovative suspension allows to overcome large obstacles and develop speed up to $30 \mathrm{~km} / \mathrm{h}$. It can also be a carrier of various detection systems.

Heavy interventions robots are not yet popular. Their tasks, especially confirming the presence of IED, in RCP patrols are currently carried out with large range manipulators $(6-8 \mathrm{~m})$ mounted on MRAP vehicles (Mine Resistant Ambush Protected) - e.g. "Buffalo". Lifting capacity of these manipulators up to a maximum range of $70 \mathrm{~kg}$ indicates that robots of less than $1000 \mathrm{~kg}$ are sufficient for this type of work- with much greater transport vulnerability. The basic parameters of such robots are summarized in Table 2. They can successfully meet the expectations in the field of digging in hard soil and taking large IEDs, placed in the ground on the route of passage of military columns. Making interventions with large range manipulators $(6-8 \mathrm{~m})$ placed on MRAP type manned vehicles, due to the small distance from the IED, is extremely dangerous and risky, especially when recognizing large loads. A similarly dangerous task in the RCP patrol is the operation of the IED detection system mounted on the second MRAP vehicle. For these reasons, the search for the possibility of carrying out these tasks with the help of heavy engineering robots is being undertaken. An example of such activities may be the robotization of the IED detection systems on the MRAP "Husky" (USA) [4] vehicle and Land Bike (GB) [5] vehicle - also the carrier of the detection system. There are also other possibilities to increase the scope of tasks carried out by engineering works, because they limit the risk for soldiers.

\section{Expected Capabilities of Heavy Engineering Robots}

The tactics of using engineering robots must be adapted to the current level of technik and technology development. Their use should be envisaged both in asymmetrical operations, low intensity conflicts and classic combat operations. The main predicted areas of application of engineering robots include:

- engineering support for patrol units of general military units;

- engineering patrolling and maintenance of roads;

- engineering patrolling of infrastructure;

- engineering patrolling of the area;

- engineering support for combat operations, especially in urbanized areas;

- road paving;

- recognition of engineering dams;

- making transitions in engineering dams.

Engineering support for patrol activities occurs mainly during asymmetrical operations. General military units patrol the area most often using full-time, armored armored vehicles that provide fire protection and support. In unfavorable conditions or in the case of the need to thoroughly check the terrain, they pass into pedestrian traffic. The biggest threat to patrols are the booby traps and IEDs. For these reasons, patrols are reinforcing the sapper section, whose task is to recognize suspected places and objects identified by general military reconnaissance and neutralization of detected traps. EOD light engineering works, which can be transported in standard military vehicles or on their armor, are used for these tasks.

These robots are expected to be highly transport-friendly, have a short time to prepare for operation and have an effective working range of 200-400 m (nominal range 400-800 m). It is recommended to equip the patrol in 2 lightweight robots with a mass of up to $15 \mathrm{~kg}$ and a portable one with a weight not exceeding $75 \mathrm{~kg}$. The first of these is expected to implement the tasks of rapid recognition and identification of threats and support activities in a rough terrain where the robot is carried by soldiers and used only temporarily for short-term missions. The purpose of a larger robot is realization the task of identifying the requiring ability to reveal hidden charges and their neutralization or transfer advanced detection and detection systems that allow for more effective protection of pedestrian patrols. The robot should have the possibility of long-lasting work enabling supporting foot patrols for a minimum of $6 \mathrm{~h}$ (desirable $10 \mathrm{~h}$ ) and develop a maximum speed comparable to that of a running soldier. Support for combat operations in the urbanized area consists mainly in detecting traps and paving passes. For these tasks can be used lightweight and portable robots but their working possibilities are too small in many situations. For these reasons, it is advisable to use robots with a mass of $\mathbf{2 5 0 - 3 0 0 ~} \mathbf{~ k g}$ (the permissible mass is limited by the load-bearing capacity of ceilings and staircases), which have much higher lifting and thrusting forces.

They are expected to be able to overcome staircases, efficiently open doors and furniture, track, and the ability to quickly inspect rooms and warehouses. This requires a large manipulator range, high stability and high maneuverability of the robot and low energy consumption. Existing pyrotechnics do not meet these requirements.

The electric drive used in robots with a weight of up to $300 \mathrm{~kg}$ allows for effective operation for about 2-3 hours and is very sensitive to reduced temperatures (at $-200 \mathrm{C}$ the battery capacity of the battery falls by $50 \%$ compared to 
the capacity at $+200 \mathrm{C})$. Hence, the ability to support activities for a long time requires the use of hybrid or combustion propulsion. As a result, the weight of a robot capable of prolonged patrolling and tasks is increased to approx. 600-800 $\mathrm{kg}$. However, it allows for a significant increase in the robot manipulator capacity and the transfer of complex threat detection systems and the effective implementation of patrol tasks.

The main task of engineering patrols is to identify terrain and infrastructure, as well as to carry out passages (paving) and to clear terrain from mines and mine traps. These tasks are performed for general military units or to unlock traffic corridors. A high rate of task implementation is recommended. Used robots should be characterized by the ability to detect and neutralize threats fast on the road and the paths and the determination of safe passages. In addition, they should be able to replace sappers during land cleaning. For this purpose, they should be characterized by very high mobility, enabling access to hard-to-reach places and the ability to carry advanced detection and neutralization systems. They should be able to support the patrol for at least 10 hours (minimum 6 hours of continuous work). The desired control range is $400-800 \mathrm{~m}$. The robots should be able to accompany the running soldiers.

Due to the transferred equipment needed capacity and work required mobility - the total mass of the platform must be at the level min. 600-800 kg.

The most complex activities that predict the use of whole robot groups are patrolling and maintaining roads including mine clearance and cleaning. It requires recognition (detection and identification) and neutralization of threats:

- in the road line;

- on the shoulder;

- in the immediate vicinity of the road.

Effective realization of this goal requires the involvement of specialized robots tailored for these specific tasks. Analyzes indicate that it is necessary to have at least 3 types of robot engineering:

- a heavy engineering and reconnaissance robot;

- a heavy engineering and intervention robot;

- a light or medium high-mobility engineering and intervention robot.

It is also advisable to have a portable or lightweight robot - transported inside the vehicle - adapted to penetrate hard to reach places.

These robots should move in a group that ensures effective cooperation. The task of a heavy engineering and reconnaissance robot is to detect and mark places with a high probability of locating mines and improvised devices on the road's crown and in its surroundings. The basic set of detectors / sensors should enable the detection of threat in the lane of vehicles with a minimum width of $3 \mathrm{~m}$. This task should be carried out by integrated detection systems using at least two types of mutually complementing sensors - eg. ground penetrating radar cooperating with a magnetic detector.

Detection of threats on the road shoulders, in the roadside ditches in culverts, under bridges and in vehicles parked on the roadside should allow a special manipulator equipped as needed with appropriate sensors and cameras observation. Its work field and kinematics should make it possible to carry out tasks without leaving the crown of the road.

The zone of the immediate vicinity of the road in the strip of 50-70 m in width should be controlled by a special, dedicated observation system using radar, infrared or thermal vision technique. ts task is to detect threats in the form of EFP, remotely controlled grenade launchers, mines with a large radius of action and improvised devices, hidden among vegetation, suspended on trees or in buildings.

It is advisable for the robot to have systems to stimulate charges in front of the vehicle and be equipped with electronic warfare elements that protect the robot from remotely controlled wireless charges.

It is anticipated that the robot should move 100-200 $\mathrm{m}$ ahead of the main group, so that if a threat is detected it is possible to take alternative combat operations - at the same time not leaving the protection zone of the grouping.

Due to the speed and efficiency of detection systems, the expected speed of the robot should be $5-20 \mathrm{~km} / \mathrm{h}$. A low signature of the robot is desirable (noise, ground pressure, vibrations, etc.) that causes ignition of igniters. It is expected that this will allow in favorable conditions to mark suspicious places without having to stop the robot from potential threat and increase the speed of task completion to $15-20 \mathrm{~km} / \mathrm{h}$.

The places indicated by the engineering and reconnaissance robot should be verified by intervention works. A heavy intervention robot with high working capacity should be used on the road crown. It should be able to dig the road surface, uncover devices, remove masking objects and push suspicious objects off the road crown. The working range of the attachments should allow inspections of roadsides and ditches. Under favorable conditions, the robot should be able to neutralize detected and recognized loads. Depending on the level of threat, this robot should follow the reconnaissance robot or be transported on a special trailer or other means of transport and proceed to act if a threat is detected.

Threats detected in the vicinity of the road should be identified and neutralized by very high mobility interventions. They should be able to overcome roadside ditches, debris, collapses, logs, etc. in order to reach the indicated places, identify the threat and, if necessary, neutralize it. The robot's working capabilities should enable neutralization of EFP-type devices and active mines with a large operating range. It is advisable that he could, under favorable conditions, take over tasks carried out by a heavy intervention robot operating on the road's crown. For these reasons, its speed should reach $15 \mathrm{~km} / \mathrm{h}$.

Command and control systems should be grouped together in a command and teleoperation vehicle. They should enable effective teleoperation of all robots, mutual transfer of information and cooperation and coordination of tasks by the commander.

In high risk or need for purification broad lanes, it should be possible to connect and cooperation of the two sets of robots. It is advisable to supplement the system with an unmanned flying vehicle (rotorcraft, helicopter) - supporting a 
group in situational awareness and control. The system should have inclusive capabilities:

- detection of tension (thin lines);

- detection of antennas and wires;

- detection of metals masked with soil;

- detection of explosives;

- CBRN detection;

- observation of low-lying objects (eg. under a car);

- observation of objects high above the robot;

- taking or removing items with a manipulator;

- uncovering objects in the ground; - excavating items;

- checking cars and trucks (chassis, interior, luggage compartment);

- checking culverts and bridges;

- IED neutralization by various methods.

As a result, the crew of the command and teleoperation vehicle should consist of at least 5 soldiers:

- commanding officer - the operator of the reconnaissance (detection and threat detection) system and the UAV (unmanned aerial platform);

- operator controlling a heavy reconnaissance robot;

- operator controlling a heavy intervention robot;

- operator controlling a light intervention robot;

- drivers of command and teleoperation vehicles

The engineering and patrol platform while working with detectors should not intervene but continue the mission of detecting threats. Critical for the implementation of the intervention mission are:

- a very large manipulator area adapted to the anticipated, varied tasks (indicated minimization of the number of degrees of freedom to simplify the control system);

- large lifting and pulling forces developed by the manipulator with high resistance to overload (this requires the use of hydrostatic drive and high stability);

- ability to overcome roadside ditches and other terrain obstacles and rubble;

- the ability to dig and loosen the ground;

- the ability to quickly engage the necessary to accomplish the task of complementarily working tools.

\section{Conclusion}

Robotization of C-IED tasks is now a necessity due to the threats. The currently used mobile and light EOD robots are not able to effectively complete all the necessary tasks. The conducted analyzes clearly show the need for introduction of heavy robots. They are useful both during removal and neutralization of UXO, as well as during the detection, identification and neutralization of IEDs. To ensure high work efficiency it is necessary to have specialized robots forming groups. It should include patrol and intervention robots.

Patrol robots should detect threats and confirm them under favorable conditions. The treats may be in the lane (usually buried in the ground or hidden in ducts and culverts), shoulders (usually masked with various objects), in vehicles set by the roads, hidden behind or inside of infrastructural objects (junction boxes, walls, fences, ground floors, etc.) and near the road - in the case of using EFP - 50-70 m from the road. The main task of the patrol platform is the detection of mines or IEDs located in the ground, on the route of marching and their marking and determining the location.

It can also verify the threat by using a patrol (reconnaissance) manipulator. The type of taken actions will depend on the tactical situation. One of the possible solutions is also not taking action and avoiding (driving around) the dangerous zone. One of the main problems for the patrol robot detection system is the lack of unambiguous characteristics of the searched objects. While in the case of mines - produced serially and in accordance with the conventions - there may be a number of characteristic shapes and the content of ferromagnetic materials, as in the case of IED, both shape, construction, material is not standard. In any case, they can take other forms and are very easily modified and adapted to local conditions which definitely makes them difficult to detect and practically eliminates the possibility of process automation. For their common feature can only be considered their considerable dimensions - comparable or much larger than anti-tank mines. The initiating systems are very diverse and are often found outside the main explosive device hence, there are often different types of wires connecting individual elements of the IED.

For these reasons, the platform should effectively detect anti-tank mines and large objects hidden in the ground. The ability to detect wires, especially those connected to electronic remote-control systems is also indicated.

Intervention robots should be able to confirm the presence of danger on the road crown and in its vicinity, thanks to the ability to quickly reach the indicated point and the ability to remove masking materials by lifting them, pulling away or digging.

In case of confirmation of occurrence, they should be able to neutralize the threat. UGV activities should be coordinated within the robot groups. Because platforms should support the activities of motorized or mechanized sub- units performing tasks also in pedestrian line, they ought to be characterized by high terrain mobility. 


\section{Acknowledgment}

The work presented in this article has been supported by the Polis National Center for Research and Development (Grant No. DOBR -BIO4/083/13431/2013).

\section{References}

1. Blokhin A., Koshurina A., Krasheninnikov M., Dorofeev R.: The Analytical Review of the Condition of Heavy Class Military and Dual Purpose Unmanned Ground Vehicle. MATEC Web of Conferences 26, 04002 (2015), EDP Sciences, 2015.

2. Bogue R.: Detecting mines and IEDs: what are the prospects for robots. The International Journal of Robotics Research and Application. Vol. 38 Issue: 5, pp.456-460.

3. Richardson C.: JIEDDO's Robotics Programs. Military Robitics Summit. 29 August 2012 Washington DC, USA.

4. Rogers P.: Future Ground Vehicle Robotics. US Army Tank-Automotive Research Development and Engineering Center. 15 July 2015.

5. Robotic and autonomous system strategy. U.S. Army Training and Doctrine Command 950 Jefferson Ave, Fort Eustis, VA 23604 March 2017. 